\title{
Production Strategy Selection and Carbon Emission Reduction with Consumer Heterogeneity under Cap-and-Trade Regulation
}

\author{
Xuzhao Li $\mathbb{D}^{\text {, }}$, Yao Tang ${ }^{(D)}$, and Yu Tang \\ Business School, University of International Business and Economics, Beijing 100029, China \\ Correspondence should be addressed to Yao Tang; tang_yao@aliyun.com
}

Received 1 October 2021; Revised 3 December 2021; Accepted 30 January 2022; Published 7 March 2022

Academic Editor: Wei Zhang

Copyright (c) 2022 Xuzhao Li et al. This is an open access article distributed under the Creative Commons Attribution License, which permits unrestricted use, distribution, and reproduction in any medium, provided the original work is properly cited.

\begin{abstract}
In literature, the firm's selection of dual-product strategy under cap-and-trade regulation and the optimal emission reduction decisions are not well studied, especially through an analytical approach. We develop a theoretic model to investigate the firm's selection on three product strategies in the presence of cap-and-trade policy, including two single product strategies and a dualproduct strategy, and identify two types of consumers: consumers with low-carbon preference and regular consumers. Our analysis shows that, (i) in the absence of cap-and-trade policy, it is optimal to adopt dual-product strategy, but in the presence of this policy, it is optimal to adopt dual-product strategy or low-carbon product strategy. (ii) Compared with ordinary product strategy, adopting a low-carbon product strategy or dual-product strategy benefits the firm under cap-and-trade regulation. (iii) The additional cost of producing low-carbon product has an impact on the firm's product strategy selection under cap-and-trade regulation. When it falls below a certain threshold, it is optimal to adopt a dual-product strategy; otherwise, it is optimal to adopt a low-carbon product strategy. Our research can provide reference for firm's decision-making and government's policy formulation.
\end{abstract}

\section{Introduction}

With the deterioration of the global environment, excessive carbon emissions have attracted increasing attention. According to $\mathrm{ABC}$ News in the US, global carbon emissions in 2020 fell $7 \%$ from 2019 levels due to COVID-19 and reached 37 billion tons. However, the long-term growth trend has not changed, and this value is expected to reach 58 billion tons by 2030 . Given the gravity of the situation, many governments have adopted measures to limit and reduce excessive carbon emissions. Among these measures, a capand-trade system, because it could encourage firms to automatically reduce carbon emissions, is considered an effective policy and has been adopted by many countries $[1,2]$. The European Union Emission Trading Scheme (EU-ETS) began to implement this policy in 2005 [3]. According to
World Bank statistics, more than 46 countries and 32 regions have implemented 61 policies addressing carbon emission reduction, of which 31 are cap-and-trade systems. In 2011, China began piloting this policy in seven provinces, including Beijing, Shanghai, and Chongqing. By the end of 2020, China's pilot area had covered approximately 3,000 firms in more than 20 industries.

In a cap-and-trade system, the firm can obtain a certain amount of free carbon emissions from the government, and if the firm's actual total emissions are below this quota, the unused remainder of the free emission quota can be sold on an emissions trading market. However, if its total emissions exceed the quota, the firm must purchase the required allowances in the carbon market. This policy places a constraint on the firm's total carbon emissions, which may increase the firm's cost to some extent. However, it also 
allows firms to trade their carbon allowances in the market, providing an opportunity to increase profits for those committed to carbon reduction.

Moreover, in recent years, some consumers' environmental consciousness has expanded substantially. An increasing number of consumers prefer environmentally friendly products and are willing to pay higher prices for them $[4,5]$. A recent survey shows that $17 \%$ of US consumers and $23 \%$ of European consumers have a preference for green products [6]. The European Commission's study is more optimistic, and they conclude that $75 \%$ of the respondents prefer to purchase green products [7]. However, these studies also imply that not all consumers have a strong environmental consciousness, and some consumers continue to have reservations about environmentally friendly products. In other words, at present, consumers are heterogeneous due to their different levels of environmental consciousness.

Influenced by the government's cap-and-trade policy and the increasing environmental awareness of consumers, some firms begin to consider taking measures to reduce their carbon emissions in the production process. Among these measures, a typical one is to shift away from ordinary product to produce low-carbon product. In this way, on the one hand, the total carbon emission can be reduced, and the impact of cap-and-trade policy on firm can be alleviated. On the other hand, the low-carbon products can meet the needs of consumers with low-carbon preferences in the market. Thus, more consumer surplus can be obtained. However, producing low-carbon products requires adopting lowcarbon technology, which will incur additional cost. Therefore, under the influence of cap-and-trade policy, the firm has to make a decision whether to continue to produce ordinary products or choose to produce low-carbon product. If it chooses to produce low-carbon products, how to make decisions on the carbon emission reduction level of products?

To address this issue, this paper developed a gametheoretic model to examine the firm's product strategy selection under the regulation of cap-and-trade policy. Specifically, we try to answer the following questions:

(i) Is the firm's optimal product strategy the same before and after the cap and trade policy is implemented?

(ii) Under cap-and-trade regulation, how does the firm choose its optimal product strategy?

(iii) What is the impact of cap-and-trade policy on the firm's decision regarding the product's optimal emission reduction?

Previous literature on firm's product strategy selection and carbon emission reduction decisions only considered the firm's choice of the single product strategy; research using analytical model to investigate the firm's choice of dual-product strategy under cap-and-trade regulation is still spare. Moreover, most of them assumed that consumers have the same preference for low-carbon product without considering the heterogeneity of consumers' preference for low-carbon product. To fill this research gap, we develop a theoretic model to investigate the firm's selection on three product strategies under cap-and-trade regulation, including two single product strategies and a dual-product strategy, and identify two types of consumers: consumers with low-carbon preference and regular consumers.

We first establish an analytical model under three product strategies (ordinary product, low-carbon product strategy, and dual-product strategy) and solve for the optimal solutions using a game theoretic approach. Then, we compare and analyze the optimal solutions under each product strategy. In addition, we compare the firm's optimal product strategies covered by cap-and-trade policy and those not covered by this policy.

The remainder of the paper proceeds as follows. We review the related literature in Section 2, and then we provide the related notations and assumptions in Section 3. In Section 4, we set up the model. In Section 5, we examine the firm's optimal solutions under each product strategy and compare them. In Section 6, we provide the numerical example for the findings. We also provide the discussion of the research results in Section 7. In Section 8, we conclude the paper.

\section{Literature Review}

There are three streams of literature that are relevant to our research, and we will review them, respectively.

The first research stream is concerned with consumers' attitude and preference for low-carbon product. Due to the direct impact of environmental pollution, as well as the advocacy of the government and environmental protection organizations, consumers are increasingly aware of environmental protection, and some consumers even have a certain purchasing preference for low-carbon product. At present, many scholars have done research on this subject. For example, Aguilar and Vlosky [8] implied that three of four of the respondents exhibit willingness to pay a $10 \%$ premium for certified wood products. Roheim et al. [9] tried to find whether the consumers would genuinely pay a premium for the green products. Their results indicate that the consumers would pay at least a $14.2 \%$ premium for the ecolabeling seafood. Kang et al. [10] concentrated on US hotel consumers' environmental consciousness and consuming behavior. Their results highlight that the consumers pay high attention to the hotel green initiatives and present willingness to pay a premium for them. Akehurst et al. [11] provided a new evidence to support the viewpoint that the ecological conscious consumers have higher intention to purchase green products. Zhang et al. [12] conducted a survey on consumers' willingness to pay a price premium for energy-saving appliances and found that consumer's environmental values can positively affect consumer's purchasing behavior. Tan et al. [13] compared consumer's price premiums for FSC Labeled Wood Flooring in five cities of China and found that some consumers indeed exhibit preference for environmentally friendly flooring. Higgins et al. [14] concluded that consumer's conservation-orientated beliefs enable them to pay a 
price premiums for Eco-Labelled forest products in Northern Ireland. From the results of above research, it is true that some consumers have purchasing preference for environmentfriendly and low-carbon products and are willing to pay a higher price for them. However, the above studies only address consumers' environmental consciousness and consumption without taking into account the heterogeneity of consumers' low-carbon preference, nor incorporating the firm's production decisions into their research framework, while the above research can help us with the setup of our model by capturing low-carbon product's attributes and consumer's preference.

The second stream is the studies on various government policies and incentive schemes to limit and constrain the firm's carbon emission. In particular, several papers studied a variety of financial incentives policies for firms, including cap-and-trade policy, carbon tax, and subsidy policy. For example, Benjaafar et al. [15] provided a comparison of the impacts of four low-carbon policies, including the cap-andtrade scheme, on firms' production and inventory decisions. Cao et al. [16] examined the different impacts of cap-andtrade policy and low-carbon subsidy policy on the firm's carbon emission reduction level. Xu et al. [17] studied the make-to-order problem of the supply chain under cap and trade regulation and provided the relevant coordination mechanism in the conclusion. Zhang [18] found that, compared with the constraint of carbon emission reduction for all industries, the government's constraint policy for enterprises with high energy consumption has a positive impact on the economy and social welfare. Zhou et al. [19] compared the effects of a flat carbon tax policy and an increasing block carbon tax policy on carbon emission reduction and social welfare and found that increasing block carbon tax policy can relieve of the manufacturer's burden. Hussain et al. [20] found that emission reduction subsidy policy enabled a firm to obtain largest profits and can ensure the adoption of green technology. Zhang et al. [21] compared the low-carbon sustainable development level of some major cities in China and identified the factors influencing the low-carbon sustainable development level of city. Yang et al. [22] identified that government subsidy policy is an effective way to incentive the firm to adopt green technology and accordingly can expand the green product market. Lu and Sun [23] examined the effects of cap-and-trade regulation and subsidy incentives on the firm's low-carbon technology level for new products. Zhang et al. [24] pointed out that carbon emission is an important factor reflecting the level of low-carbon sustainable development of the firm and concluded that government policies can effectively promote the firm to reduce carbon emission. While all the above papers used empirical or simulation approaches to investigate various government policies' effects on firm's carbon emission reduction decisions, researches studying the influence of cap-and-trade policy on the product selection strategy and carbon emission reduction decisions are quite limited.

The third research stream uses analytical models to study the firm's operation decisions under the government's policy in terms of carbon emission reduction. A number of researchers addressed the traditional operation decisions under the government's policies, including pricing, production, and inventory decisions [25-28]. However, there are indeed some scholars who have studied the firm's choice of low-carbon product strategy or green technology strategy under the influence of government policies. For instance, $\mathrm{Du}$ et al. [29] found that, under cap-and-trade regulation, adopting low-carbon production strategy can improve the firm's profits to a certain extent, and the cap-and-trade policy can effectively reduce the firm's total carbon emissions, which is consistent with our conclusions. Du et al. [29] assumed that all consumers give higher evaluation to lowcarbon products than ordinary products. Different from $\mathrm{Du}$ et al. [29], we divided consumers into two categories: consumers with preference for low-carbon products and ordinary consumers without preference. Meng et al. [30] examined the firm's carbon emission reduction decisions and product strategy selection under the influence of carbon tax policy. They assumed that the firm has a choice between common products and low-carbon products. However, our study examines the firm's choice of three product strategies. In addition, they mainly studied the impact of carbon tax rate on product strategy selection, while our study focused on the impact of cap-and-trade policy on the firm's product strategy selection. Zhang et al. [31] investigated whether the firm should adopt green technology to reduce carbon emissions or directly purchase carbon quota under cap-andtrade regulation, which is similar to our research theme. However, Zhang's research mainly focuses on the impact of consumers' low-carbon preference on the firm's strategy selection, while our research mainly focuses on the influence of cap-and-trade policy on the firm's strategy selection and emission reduction decision. Zhang et al. [32] also studied whether the firm should invest in green technology to reduce carbon emissions and found that it is not beneficial to the manufacturer when the cost is relatively high. We differ from Zhang et al. [32] in that we consider the firm under the regulation of cap-and-trade policy, while Zhang et al. [32] does not consider the influence of government policy.

From the analysis above, it can be seen that although many scholars have studied the firm's choice of low-carbon production or green technology strategy under the influence of government policies, they did not consider the choice of dual-product product strategy under cap-and-trade regulation. To fill the gap, we establish theoretic model to explore the firm's optimal product strategy by considering three product strategies and two types of consumers, and, furthermore, we examine the impact of cap-and-trade policy on the firm's product strategy selection and emission reduction of product, which we believe adds a good contribution to the existing literature.

\section{Notations and Assumptions}

We summarize the notations in Table 1.

3.1. Assumptions. To establish the model, we make the following assumptions: 
Assumption 1. The additional cost of low-carbon technology improvement for producing low-carbon products is assumed to be a quadratic function $1 / 2 k e^{2}$. A similar assumption can be found in many recent studies $[33,34]$.

Assumption 2. We assume that the carbon emissions of the low-carbon product are lower than those of the ordinary product. In other words, in equilibrium, the carbon emission reduction level of the low-carbon product should be greater than zero.

Assumption 3. We assume that when the firm adopts the ordinary product strategy, low-carbon product strategy, or dual-product strategy, in equilibrium, product demand is greater than zero.

\section{Model Description}

4.1. Consumer Utility. Consumers with low-carbon preferences have strong environmental consciousness and prefer to purchase low-carbon products. Regular consumers are those with low environmental consciousness, and they have no obvious preference for the low-carbon product. We assume the total market size to be 1, the proportion of consumers with low-carbon preferences to be $r$, and the proportion of regular consumers to be $1-r$.

Denote by $v$ the valuation of consumers with low-carbon preference for the ordinary product, which follows a uniform distribution of $[0,1]$. Since they prefer to purchase a low-carbon product, they will obtain additional utility when purchasing a low-carbon product. We assume that their evaluation for a low-carbon product is $v+a e$, where $a e$ is the additional utility they obtain. $e$ represents the carbon emission reduction level per unit of low-carbon product compared with ordinary product, and $a$ describes the sensitivity of consumers with low-carbon preference to the emission reduction level of the product $(0<a<1)$. A larger value of $a$ indicates that these consumers have a greater preference for low-carbon products, and a larger value of $e$ indicates that they obtain more utility from purchasing lowcarbon products. Then, the net utility that consumers with low-carbon preference obtain from purchasing ordinary products is $v-p$ and that from purchasing low-carbon products is $v+a e-p$. Regular consumers have no preference for low-carbon products. There is no difference between their evaluation of low-carbon products and ordinary products. Their evaluation for both products is $v$, and they can obtain net utility $v-p$ from purchasing both products.

4.2. The Product Strategy of the Firm. If the firm produces a low-carbon product, it will incur an additional one-time investment cost $1 / 2 k e^{2}$. The parameter $k$ is referred to as the cost effectiveness of carbon emission reduction $(k>0)$. Additionally, we define $e_{0}$ as the carbon emissions of the ordinary product in the production process and $e$ as the carbon emission reduction level compared with the ordinary product $\left(e_{0}>e\right)$, which is also the firm's decision-making variable. Therefore, the carbon emissions of the low-carbon product are $e_{0}-e$. Moreover, under cap-and-trade regulation, when total carbon emissions are lower than the free emission quota, the firm can sell the unused emission allowance in the market at price $t(t>0)$. To avoid trivial outcomes, we also assume that $a-t>0$.

\section{The Firm's Product Strategy}

In this section, we mainly examine the firm's two single product strategies and a dual-product strategy, as well as the optimal decisions under each product strategy in a monopoly market.

5.1. Single Product Strategy. When the firm adopts a single product strategy, there are two strategies to choose. One is the ordinary product strategy; that is, the firm only produces ordinary products; the other is the low-carbon product strategy; that is, the firm only produces low-carbon products.

If the firm adopts an ordinary product strategy, both consumers with low-carbon preferences and regular consumers will choose to purchase ordinary products. Consumers with low-carbon preferences prefer to purchase lowcarbon products. However, we assume that this is a monopoly market and that the firm does not provide a lowcarbon product, so consumers with a low-carbon preference have no choice but to purchase ordinary products together with regular consumers. Thus, both types of consumers have the same valuation $v$ for ordinary products, so we can regard current consumers as homogeneous. In addition, the value of $r$ is 0 . Furthermore, under an ordinary product strategy, the firm does not reduce the product's carbon emission level, and the present carbon emission level of the product is still $e_{0}$, which means that the value of $e$ is 0 . The firm first announces the product price $p_{1}$ and then brings the product to market. After learning the product price, consumers decide whether to buy the product according to their own utility.

Since both types of consumers have the same valuation $v$ for ordinary products, and price is the only factor that affects consumers' purchasing decisions, we assume that each consumer follows a simple decision rule: if his or her valuation $v$ equals or exceeds the offered product price $p_{1}$, the customer will purchase the product; otherwise, he or she will leave the system. Moreover, each consumer purchases at most one unit of the product. Since consumers' valuations are uniformly distributed from 0 to 1 with a density of 1 , this implies that $1-p_{1}$ consumers will purchase the product. Therefore, we can derive the product's demand function $D_{1}=1-p_{1}$ (i.e., we use the subscript " 1 " to represent the variables under the ordinary product strategy). Such a uniform distribution setting is widely used in marketingrelated studies.

On the basis of the demand function, the firm's profit can be modeled as

$$
\pi_{1}=\left(p_{1}-c\right) D_{1}-t\left(e_{0} D_{1}-Q\right) .
$$

The first section on the right side of above equation represents the benefit obtained by producing ordinary 
TABLE 1: Notations.

\begin{tabular}{lc}
\hline Notation & Description \\
\hline$v$ & Consumers' evaluation for the ordinary product \\
$e_{0}$ & Carbon emission reduction level of the low-carbon product \\
$a$ & Carbon emissions of the ordinary product in the production process \\
$t$ & Preference coefficient of the consumers with a low-carbon preference \\
$Q$ & Unit carbon price in the trading market under cap-and-trade regulation \\
$1 / 2 k e^{2}$ & The firm's free emission quota allocated by the government \\
$c$ & Additional cost for low-carbon technology improvement \\
$k$ & The marginal cost of a unit of product \\
$r$ & Coefficient for the additional cost of low-carbon technology improvement \\
$1-r$ & The proportion of consumers with low-carbon preferences in the market \\
$p$ & The proportion of regular consumers in the market \\
$D$ & The price of the product \\
$\pi$ & The demand for the product \\
\hline
\end{tabular}

products, while the second section represents the firm's increased cost or benefit under the influence of cap-andtrade policy. Then, we can derive the optimal product price, demand, and firm profit. They are $p_{1}{ }^{*}=\left(e_{0} t+\right.$ $c+1) / 2 D_{1}{ }^{*}=\left(1-e_{0} t-c\right) / 2 \pi_{1}{ }^{*}=\left(\left(e_{0} t+c-1\right)^{2}+t Q\right) / 4$

If the firm chooses a low-carbon product strategy, the valuation of consumers with low-carbon preference for lowcarbon products is $v+a e$, while that of regular consumers for low-carbon product is still $v$. Then, we can regard current consumers as heterogeneous, and the value of $r$ varies in the range $[0,1]$. The firm reduces the carbon emissions of the product in the production process, and the value of $e$ varies in the range $\left[0, e_{0}\right]$ (i.e., we use the subscript " 2 " to represent the variables under the low-carbon product strategy).

Under a low-carbon product strategy, the firm first announces the carbon emission reduction level $e_{2}$, sets the product price $p_{2}$, and then places the product on the market. However, producing a low-carbon product requires the implementation of low-carbon technology, which entails additional technology improvement costs $1 / 2 k e_{2}^{2}$. After observing the product price and carbon emission reduction level, consumers decide whether to buy the product based on their own utility.

The sequence of events in this scenario is shown in Figure 1.

When purchasing low-carbon products, the net utility of consumers with low-carbon preferences is $v+a e_{2}-p_{2}$ and that of regular consumers is $v-p_{2}$. Similar to the process of deducing the demand function in Section 5.1, the demand for the low-carbon product can be derived as $D_{2}=r\left(1-p_{2}+a e_{2}\right)+(1-r)\left(1-p_{2}\right)$, and the firm's profit is

$$
\pi_{2}=\left(p_{2}-c\right) D_{2}-t\left[\left(e_{0}-e_{2}\right) D_{2}-Q\right]-\frac{1}{2} k e_{2}^{2} .
$$

The first section on the right side of above equation represents the benefit obtained by producing a low-carbon product, the second section represents the firm's increased cost or benefit under the influence of the cap-and-trade policy, and the third section represents the additional cost of technology improvement for producing a low-carbon product. Then, we can derive the optimal product price, demand, and firm profit under a low-carbon product strategy, which are shown in Lemma 1.

Lemma 1. The optimal emission reduction level $e_{2}{ }^{*}$, product price $p_{2}{ }^{*}$, product demand $D_{2}{ }^{*}$ and profit $\pi_{2}{ }^{*}$ are

$$
\begin{aligned}
& e_{2}{ }^{*}=\frac{(a r+t)\left(e_{0} t+c-1\right)}{(a r+t)^{2}-2 k} ; \\
& {p_{2}}^{*}=\frac{(a r+t)\left(a e_{0} r t+a c r+t\right)-k\left(e_{0} t+c-1\right)}{(a r+t)^{2}-2 k} ; \\
& D_{2}{ }^{*}=\frac{k\left(e_{0} t+c-1\right)}{(a r+t)^{2}-2 k} ; \\
& \pi_{2}{ }^{*}=\frac{1}{2} \frac{2 Q t\left[(a r+t)^{2}-2 k\right]-k\left(e_{0} t+c-1\right)^{2}}{(a r+t)^{2}-2 k} .
\end{aligned}
$$

5.2. Dual-Product Strategy. We next consider the situation in which the firm adopts a dual-product strategy to produce two types of products (i.e., we use the subscript " 0 " to represent the variables for the ordinary product, and " $L$ " to represent the variables for the low-carbon product). The firm still needs to implement low-carbon technology improvement and faces additional costs. The firm first determines the carbon emission reduction level $e_{3}$ of the low-carbon product, then sets the prices of two types of products (i.e., we denote by $p_{0}$ the price of the ordinary product and by $p_{L}$ the price of low-carbon product), and finally places both on the market. After observing the prices and the carbon emission reduction level, consumers make their purchasing decisions (Figure 2).

Consumers with low-carbon preferences obtain net utility $v-p_{L}+a e_{3}$ from buying the low-carbon product and $v-p_{0}$ from buying the ordinary product. Regular consumers obtain net utility $v-p_{L}$ from buying the low-carbon product and $v-p_{0}$ from buying the ordinary product. For consumers with a low-carbon preference, if $v-p_{L}+a e_{3}>v-p_{0}$, they will buy the low-carbon product. If $v-p_{0}>v-p_{L}+a e_{3}$, they will choose the ordinary 


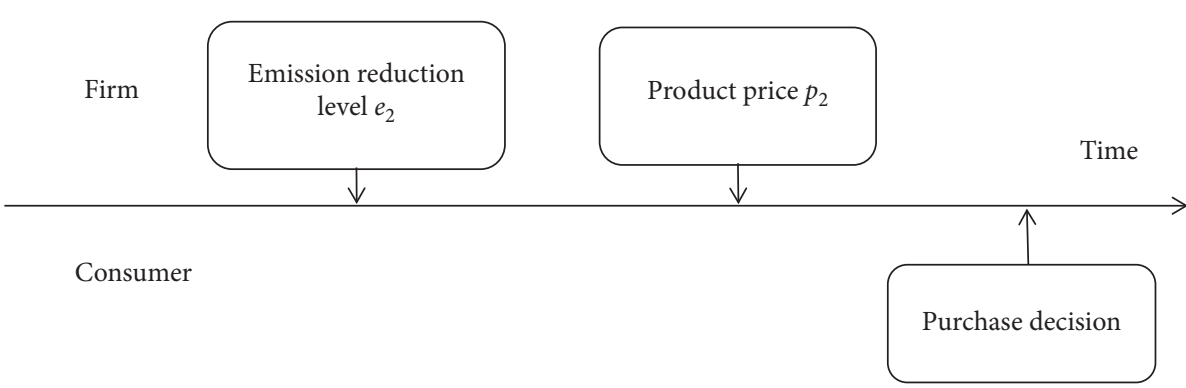

FIgURE 1: Sequence of events under the low-carbon product strategy.

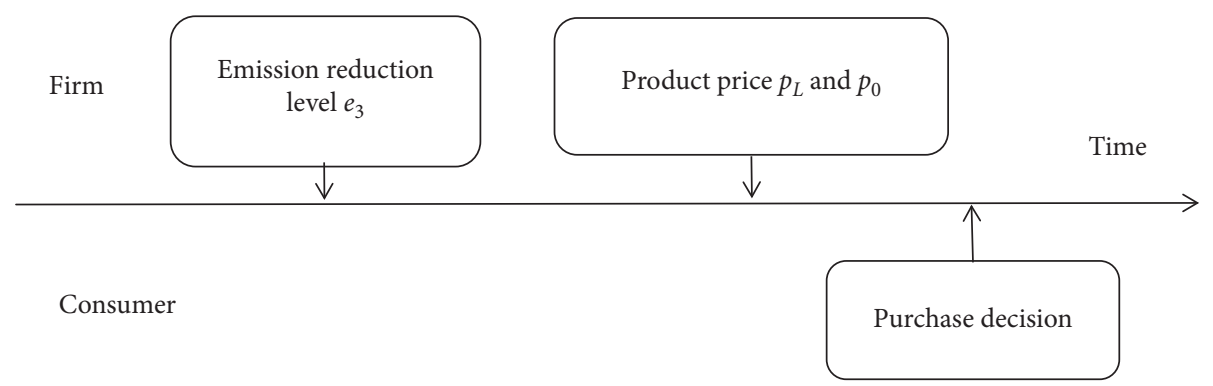

Figure 2: Sequence of events under the dual-product strategy.

product. For regular consumers, if $v-p_{L}>v-p_{0}$, they will also choose the low-carbon product. If $v-p_{0}>v-p_{L}$, they will choose the ordinary product.

Therefore, three situations may occur.

First, both types of consumers choose the low-carbon product. The ordinary product is driven out of the market, and only the low-carbon product remains (i.e., $p_{L}<p_{0}$ is true).

Second, consumers with low-carbon preferences choose the low-carbon product, while regular consumers choose the ordinary product. The two types of products coexist in the market (i.e., $p_{0} \leq p_{L} \leq p_{0}+a e_{3}$ is true).

Third, both types of consumers choose the ordinary product. The low-carbon product is driven out of the market, and only the ordinary product remains (i.e., $p_{L}>p_{0}+a e_{3}$ is true).

Therefore, we can derive the product demands:

$\left(D_{0}, D_{L}\right)=\left[\begin{array}{ll}{\left[0, r\left(1-p_{L}+a e_{3}\right)+(1-r)\left(1-p_{L}\right)\right]} & p_{L}<p_{0} \\ {\left[(1-r)\left(1-p_{0}\right), r\left(1-p_{L}+a e_{3}\right)\right]} & p_{0} \leq p_{L} \leq p_{0}+a e_{3} . \\ {\left[1-p_{0}, 0\right]} & p_{L}>p_{0}+a e_{3}\end{array}\right.$

Only in the second situation do both types of products coexist in the market, so the firm can adopt a dual-product strategy. Our study will focus on this situation, and the firm's profit function can be derived as follows:

$$
\pi_{3}=\left(p_{0}-c\right) D_{0}+\left(p_{L}-c\right) D_{L}-t\left[e_{0} D_{0}+\left(e_{0}-e_{3}\right) D_{L}-Q\right]-\frac{1}{2} k e_{3}^{2}
$$

From the above equation, we can see that the firm's benefit comes from both ordinary product and low-carbon product it produces, and the total carbon emission also comes from producing two types of products. By calculation, we obtain Lemma 2.
Lemma 2. We can derive the optimal pricing strategy $p_{0}{ }^{*}$ and $p_{L}{ }^{*}$, the carbon emission reduction level of the low-carbon product $e_{3}{ }^{*}$, the product demand, and the profit $\pi_{3}{ }^{*}$ (i.e., we made a verification and found that the values of $p_{0}{ }^{*}$ and $p_{L}{ }^{*}$ satisfy this condition $p_{0} \leq p_{L} \leq p_{0}+a e_{3}$, and we added the proof in Appendix B):

$$
\begin{aligned}
p_{0}{ }^{*} & =\frac{1}{2}\left(e_{0} t+c+1\right) ; \\
p_{L}{ }^{*} & =\frac{r(a+t)\left(a e_{0} t+a c+t\right)-k\left(e_{0} t+c+1\right)}{r(a+t)^{2}-2 k} ; \\
e_{3}{ }^{*} & =\frac{r(a+t)\left(e_{0} t+c+1\right)}{r(a+t)^{2}-2 k} ; \\
D_{0}{ }^{*} & =\frac{1}{2}(1-r)\left(e_{0} t+c+1\right) ; \\
D_{L}{ }^{*} & =\frac{r k\left(e_{0} t+c+1\right)}{r(a+t)^{2}-2 k} ; \\
\pi_{3}{ }^{*} & =\frac{1}{4} \frac{4 Q t\left[r(a+t)^{2}-2 k\right]-\left(e_{0} t+c+1\right)^{2}\left[r(a+t)^{2}(r-1)+2 k\right]}{r(a+t)^{2}-2 k} .
\end{aligned}
$$

We consider that there are the two types of consumers in the market, and the proportion of consumers with lowcarbon preference in the market also has a certain impact on the firm's decisions. By studying the impact of this proportion on the product demands and carbon emission reduction level of low-carbon products, we obtain Propositions 1 and 2.

\section{Proposition 1}

(i) When the firm adopts the low-carbon product strategy, an increase in the share of consumers with a 
low-carbon preference in the market will increase the demand for the low-carbon product, i.e., $\partial D_{2} * / \partial r>0$

(ii) When the firm adopts the dual-product strategy, an increase in the share of consumers with low-carbon preferences in the market will increase the demand for the low-carbon product and decrease the demand for the ordinary product, i.e., $\partial D_{L} * / \partial r>0, \partial D_{0} * / \partial r>0$

When the firm adopts low-carbon product strategy, the firm only produces low-carbon product, and two types of consumers choose to buy low-carbon product based on their own utility. As $r$ increases, it indicates that the proportion of consumers with low-carbon preference in the market increases, while the proportion of regular consumers decreases. Therefore, the product demand coming from consumers with low-carbon preferences will gradually increase, while that coming from regular consumers will gradually decrease. Since consumers with low-carbon preference obtain more net utility than regular consumer without preference when buying low-carbon product, the increased product demand from consumers with low-carbon preference will be greater than the reduced product demand from regular consumers. Therefore, the total demand for low-carbon product is increased.

When the firm adopts the dual-product strategy, the demand for low-carbon product comes from consumers with low-carbon preference, while the demand for ordinary product comes from regular consumers without preference. Therefore, when the proportion of consumers with lowcarbon preference in the market increases, the demand coming from consumers with low-carbon preference for low-carbon product will also increase. When the proportion of regular consumers in the market decrease, the demand coming from regular consumers for ordinary product will also decrease.

\section{Proposition 2}

(i) When the firm adopts the low-carbon product strategy, an increase in the share of consumers with a low-carbon preference in the market will motivate the firm to improve the carbon emission reduction level of the low-carbon product, i.e., $\partial e_{2}{ }^{*} / \partial r>0$

(ii) When the firm adopts the dual-product strategy, an increase in the share of consumers with low-carbon preferences in the market will also motivate the firm to improve the carbon emission reduction level of the low-carbon product, i.e., $\partial e_{3}{ }^{*} / \partial r>0$

Since we have proved that, under low-carbon product strategy, as $r$ increases, the increased product demand from consumers with low-carbon preference is greater than the reduced product demand from regular consumers, which ultimately leads to the increase of the total demand for lowcarbon product. The reason is that consumers with lowcarbon preference are sensitive to the carbon emission reduction level of the product, and then improving the carbon emission reduction level of product can make them obtain greater net utility and increase their demand for low-carbon product. For the firm, increasing the demand for products is always beneficial. Therefore, in order to better meet the needs of consumers with low-carbon preferences, the firm will try to improve the carbon emission reduction level of the product. In addition, we have proved that, under dualproduct strategy, as $r$ increases, consumers with low-carbon preference will increase their demand for low-carbon product. Similarly, in order to better meet their needs, the firm will also try to improve the carbon emission reduction level of their products.

In this section, we mainly analyze the results of the models described in Section 5. To obtain managerial insights, this section compares the optimal decisions and profits under each strategy. The purpose of the cap-andtrade policy implemented by the government is to encourage firms to reduce the product's carbon emissions in the production process by allocating a limited free carbon quota, which also has a serious impact on the firm's profits. To study the impact of this policy on firms' profits, it is necessary to make a comparative analysis of the firm's profits covered by the cap-and-trade policy and those not covered by this policy (i.e., we use the subscript " $N$ " to represent the variables not under the influence of the cap-and-trade policy, and we attach the profit function under each product strategy in Appendix A). We first calculate the firm's profits not covered by the cap-and-trade policy under three product strategies (see Table 2).

By comparing a firm's profits not covered by the capand-trade policy with those covered by this policy under each product strategy, we can obtain Proposition 3.

\section{Proposition 3}

(i) When the firm adopts the ordinary product strategy, if the quota allocated by the government $Q$ is greater than threshold $Q_{1}$, the firm's profit covered by capand-trade policy will exceed the profits not covered by this policy, i.e., $\pi_{1}{ }^{*}>\pi_{N 1}{ }^{*}$; otherwise, the opposite is true

(ii) When the firm adopts the low-carbon product strategy, if the quota allocated $Q$ is greater than threshold $Q_{2}$, the firm's profit covered by the capand-trade policy will exceed the profits not covered by this policy, i.e., $\pi_{2}{ }^{*}>\pi_{\mathrm{N} 2}{ }^{*}$; otherwise, the opposite is true

(iii) When the firm adopts the dual-product strategy, if the quota allocated $Q$ is greater than threshold $Q_{3}$, the firm's profit covered by the cap-and-trade policy will exceed the profits not covered by this policy, i.e., $\pi_{3}{ }^{*}>\pi_{N 3}{ }^{*}$; otherwise, the opposite is true

From Proposition 3, we find that the carbon quota allocated by the government has a decisive impact on the firm's profits. Regardless of whether the firm adopts the ordinary product strategy, low-carbon product strategy, or dual-product strategy, as long as the carbon quota allocated by the government is higher than a certain value, the firm's 
TABLE 2: Firm's profits not covered by the cap-and-trade policy under three product strategies.

\begin{tabular}{lc}
\hline Product strategy & $\pi$ \\
\hline $\begin{array}{l}\text { Ordinary product } \\
\text { strategy }\end{array}$ & $\pi_{N 1}=(1 / 2-1 / 2 c)^{2}$ \\
$\begin{array}{l}\text { Low-carbon } \\
\text { strategy }\end{array}$ & $\pi_{N 2}=-1 / 2 k(c-1)^{2} / a^{2} r^{2}-2 k$ \\
$\begin{array}{l}\text { Dual-product } \\
\text { strategy }\end{array}$ & $\pi_{N 3}=-1 / 4(c-1)\left(a^{2} r^{2}-a^{2} r+2 k\right) / a^{2} r-2 k$ \\
\hline
\end{tabular}

profits covered by the cap-and-trade policy will be higher than the profits not covered by the policy. Otherwise, the firm profits will be lower than those not covered by this policy.

This is because the amount of carbon quotas allocated by the government has a direct impact on a firm's profits. Under the influence of the cap-and-trade policy, if the firm's actual total carbon emission is lower than the quota, the firm can sell the remaining unused allowance in the market to gain profits; if the actual total carbon emission is higher than the quota, the firm has to buy the required quota in the market, which will increase the cost of the firm.

When the firm is under the influence of cap-and-trade policy, no matter which product strategy the firm adopts, it always sets an upper limit for the firm's total carbon emission by allocating the carbon quota. When the quota allocated by the government is higher than a certain value, the firm's actual carbon emission is lower than the quota, and the firm may have unused quota to sell. As a result, the firm's profit covered by the cap-and-trade policy will be higher than that not covered by this policy; if the carbon quota allocated by the government is equal to this specific value, the firm's actual carbon emission is the same as the carbon quota. The firm does not need to buy the required carbon quota, and there is no remaining unused carbon quota to sell. As a result, the firm's profit covered by the capand-trade policy is the same as that not covered by this policy; when the quota allocated by the government is lower than this certain value, the firm's actual carbon emission is higher than the quota. Whether the firm purchases the required quota or takes measures to reduce the actual carbon emissions, it will increase the firm's cost, which will cause the firm's profit to be lower than that not covered this policy. In short, the more carbon quota the firm obtains, the more likely it is to increase profits.

When the firm is not under the influence of the cap-andtrade policy, by comparing the firm's profits under each product strategy, we can obtain Proposition 4.

Proposition 4. When the firm is not under the influence of the cap-and-trade policy, the firm's profit under the dualproduct strategy is greater than that under the low-carbon product strategy, while the profit under the low-carbon product strategy is greater than that under the ordinary product strategy, i.e., $\pi_{N 3}{ }^{*}>\pi_{N 2}{ }^{*}>\pi_{N 1}{ }^{*}$.

Proposition 4 shows that the firm's profit under the dualproduct strategy is greater than that under the low-carbon product strategy. This is because there are still some regular consumers who have no preference for low-carbon products in the market. When the firm adopts a low-carbon product strategy, to gain more profit from consumers with a lowcarbon preference, the firm will increase the product price. As a result, the regular consumer's demand for the product will be reduced, and the regular consumer's price elasticity is relatively large, so the profit from regular consumers will be reduced. However, if the firm adopts a dual-product strategy, the firm produces both ordinary and low-carbon products at the same time, and the price of ordinary products is lower than that of low-carbon products, so the product demand from regular consumers will be increased. Meanwhile, the firm can still keep the price of low-carbon products high, so that the firm can maximize its profits from both types of consumers. Therefore, the total profit under the dual-product strategy will be higher than that under the lowcarbon product strategy.

In addition, Proposition 4 states that the firm's profit under a low-carbon product strategy is greater than that under an ordinary product strategy. This is because there are still some consumers with low-carbon preferences in the market who give priority low-carbon products and are willing to pay higher prices for them. However, under the ordinary product strategy, the firm only produces ordinary products, so their purchasing preference for low-carbon products cannot be released. Once the firm adopts a lowcarbon product strategy, consumers' preference for lowcarbon products will be transformed into demand for lowcarbon products, so that the demand for products will be increased. Furthermore, to obtain more consumer surplus, the firm will take the opportunity to raise the product price. Although the firm has to pay some additional cost for producing low-carbon products, the total profit will be increased.

In the following, we will conduct a comparative analysis of the firm's optimal decisions and profits under the influence of the cap-and-trade policy. When the firm is covered by a cap-and-trade policy, regardless of which product strategy is adopted, the firm will first make decisions on the prices of the products or the carbon emission reduction level of the product, which will accordingly influence the demand for the product and finally influence the total profit. Therefore, we need to compare and analyze the product prices, demands, and firm's total profits under each product strategy. By comparing the prices and demands under the dual-product strategy and the ordinary product strategy, we obtain Proposition 5.

Proposition 5. When the firm adopts the low-carbon product strategy, compared with the ordinary product strategy, we have the following:

(i) The firm can expand product demand by adopting the low-carbon product strategy, i.e., $D_{2}{ }^{*}>D_{1}{ }^{*}$

(ii) When the unit carbon price $t$ is lower than the threshold $t_{1}$, the firm charges a higher price under the low-carbon strategy than under the ordinary product 
strategy, i.e., $p_{2} *>p_{1} *$; otherwise, the opposite is true

This is because consumers with low-carbon preferences in the market have a higher valuation of the low-carbon product, which enables them to obtain higher utility. If the firm only produces the ordinary product, their low-carbon preference cannot be converted into demand, and they have to buy the ordinary product alongside the regular consumers. Once the firm shifts to produce the low-carbon product, their low-carbon preference will be converted into demand for the low-carbon product, which will inevitably lead to expanded product demand. Proposition 5 also shows that the product price is related to parameter $t$. Intuitively, the total cost of producing low-carbon products is higher than that of producing ordinary products. Therefore, when the firm adopts a low-carbon product strategy, the price of low-carbon products should be increased to compensate for the production cost. However, it should be pointed out that the firm is under the influence of a cap-and-trade policy, and when the firm adopts a low-carbon product strategy, the product's carbon emissions will be reduced. If the total carbon emissions are lower than the quota allocated by the government, the firm can sell the unused carbon allowance in the market to obtain more profit. If the unit carbon price in the market is low, the firm can earn less profit from selling unused carbon allowances and cannot make up for the increased cost of producing low-carbon products, and the firm will have to raise the price of low-carbon products. In contrast, if the unit carbon price is high, the profits obtained from selling unused carbon quotas are more than the increased cost of producing low-carbon products. To obtain more consumer surplus, the firm will reduce the price of low-carbon products. Comparing the prices and demands under the dual-product strategy and the ordinary product strategy, we obtain Proposition 6.

Proposition 6. When the firm adopts the dual-product strategy, compared with the ordinary product strategy, we have the following: (i) the price of the ordinary product remains unchanged, i.e., $p_{0}{ }^{*}=p_{1}{ }^{*}$; (ii) the demand for the ordinary product is decreased, i.e., $D_{0}{ }^{*}<D_{1}{ }^{*}$.

Proposition 6 shows that the ordinary product price is equal to that under the ordinary strategy. Because there are some regular consumers in the market, to extract more surplus from them, the firm still produces some of the ordinary products together with the low-carbon product and charges the same price. It does so because if the firm raises the price, their demand may be directly reduced. When the demand elasticity is relatively large, the profit obtained from regular consumers will decrease sharply. The precondition for the firm to adopt the dual-product strategy is that the ordinary product's price is lower than that of the low-carbon product; otherwise, regular consumers will not choose the ordinary product. If the ordinary product's price is raised but remains lower than that of the low-carbon product, regular consumers will have less demand for the ordinary product, and those who do not buy the ordinary products will not instead buy the low-carbon product but will be directly lost. Proposition 6 also shows that the demand for the ordinary product will be lower than that under the ordinary product strategy. This is because when the firm adopts the ordinary product strategy, in addition to regular consumers, there are still some consumers with low-carbon preferences. Once the firm adopts the dual-product strategy, although the low-carbon product's price is higher, consumers with a low-carbon preference who previously purchased the ordinary product will switch to the low-carbon product, so the total demand for the ordinary product will decrease. Comparing the prices and demands under the dual-product strategy and the low-carbon strategy, we obtain Proposition 7.

Proposition 7. When the firm adopts the dual-product strategy, compared with the low-carbon strategy, we have the following: (i) the price of low-carbon product is increased, i.e., $p_{L}{ }^{*}>p_{2}{ }^{*}$; (ii) the demand for the low-carbon product is decreased, i.e., $D_{L}{ }^{*}<D_{2}{ }^{*}$.

Proposition 7 shows that, under the dual-product strategy, the price of the low-carbon product is increased compared with that under the low-carbon strategy. This is because when the firm adopts a dual-product strategy, to ensure that both ordinary products and low-carbon products have demands in the market, that is, to ensure that regular consumers who previously bought low-carbon products should switch to ordinary products, the firm will strategically increase the price of low-carbon products. Proposition 7 also shows that, under the dual-product strategy, compared with the low-carbon product strategy, the demand for low-carbon products will decrease. This is because, under the low-carbon product strategy, the firm only produces low-carbon products, and both consumers with low-carbon preferences and regular consumers have to choose to purchase low-carbon products. When the firm adopts a dual-product strategy, to ensure that both ordinary products and low-carbon products have demand, the firm will adjust the product prices to ensure that consumers with low-carbon preferences choose to purchase low-carbon products and regular consumers choose to purchase ordinary products. In that case, some regular consumers who used to buy low-carbon products will switch to ordinary products, so the demand for low-carbon products will decrease. By comparing the carbon emission reduction level of low-carbon products under the dual-product strategy and the low-carbon strategy, we obtain Proposition 8.

Proposition 8. When the unit carbon price in market $t$ is higher than the threshold $t_{2}$, the carbon emission reduction level of the low-carbon product under the dual-product strategy is higher than that under the low-carbon strategy, i.e., $e_{3} *>e_{2} *$; otherwise, the opposite is true, i.e., $e_{3} *<e_{2} *$.

This is because if the unit carbon price in the trading market is high, whether the firm's actual total carbon emissions are higher or lower than the quota allocated by the government, the unit carbon price has a great impact on the 
profit of the firm. If the firm's total carbon emissions are higher than the carbon quota, the firm will have to buy the required quota in the market, and the high carbon price will greatly increase the cost of the firm. If the total carbon emissions are below the quota, the firm will sell the unused quota in the market, and the high carbon price will make the firm more profitable. Recall that there are two main factors that affect the total carbon emissions of the firm. One is the production quantity of low-carbon products, and the other is the carbon emission reduction level of low-carbon products. Under the dual-product strategy, the demand for low-carbon products is lower than that under the lowcarbon product strategy. In this case, to reduce total carbon emissions, the firm will strive to improve the carbon emission reduction level of low-carbon products. In contrast, if the unit carbon price is low, whether the total carbon emission of the firm is higher or lower than the carbon quota allocated by the government, the impact on the total profits is relatively small. Although the demand for low-carbon products under the dual-product strategy is lower than that under the low-carbon product strategy, the firm has less motivation to improve the carbon emission reduction level of low-carbon products, so the carbon emission reduction level of low-carbon products will be lower than that under the low-carbon product strategy. We obtain Proposition 9 by comparing the profits under the low-carbon product strategy and the ordinary product strategy.

Proposition 9. The firm gains more profit by adopting the low-carbon product strategy than by adopting the ordinary product strategy, i.e., $\pi_{2}{ }^{*}>\pi_{1}{ }^{*}$.

This is because the firm can benefit in two ways. First, the low-carbon product strategy helps the firm expand market demand, as stated in Proposition 5. Second, the firm can benefit from the cap-and-trade regulation. Although producing a low-carbon product will incur some additional cost, the firm can reduce carbon emissions in the production process. When the total emissions are lower than the quota, the unused allowances can be sold in the carbon market to earn more profits. If the increased profit dominates the costs of the low-carbon technology improvement, this approach will eventually be beneficial for the firm. We obtain Proposition 10 by comparing the profits under the dual-product strategy and the ordinary product strategy.

Proposition 10. The firm gains more profit by adopting the dual-product strategy than under the ordinary product strategy, i.e., $\pi_{3}{ }^{*}>\pi_{1}{ }^{*}$.

Compared with the ordinary product strategy, the demand for the ordinary product is reduced, while the price remains unchanged under the dual-product strategy, as stated in Proposition 7, indicating that the profit from producing the ordinary product is reduced. However, the firm also produces the low-carbon product, and consumers with low-carbon preferences are willing to pay a higher price for it, meaning that the firm can earn more profit. Furthermore, under the influence of the cap-and-trade policy, the firm can save expenditures on carbon emissions and even make profits. When the added profit can offset or even dominate the loss due to the reduced demand for the ordinary product and the additional cost of the technology improvement, the firm's overall profit will be increased. We obtain Proposition 11 by comparing the profits under the dual-product strategy and low-carbon product strategy.

Proposition 11. When the firm faces a choice regarding whether to adopt the low-carbon product strategy or dualproduct strategy, there exists a threshold $k_{1}$, and we have the following: if the cost coefficient of low-carbon technology improvement is higher than the threshold $k_{1}$, it is optimal for the firm to adopt the low-carbon product strategy. i.e., $\pi_{3}{ }^{*}<\pi_{2}{ }^{*}$; otherwise, it is optimal to adopt the dual-product strategy, i.e., $\pi_{3}{ }^{*}>\pi_{2}{ }^{*}$.

Proposition 11 states that the choice between the lowcarbon product strategy and the dual-product strategy depends on the additional cost for low-carbon technology improvement.

This is because when the additional cost for producing low-carbon products is high, to compensate for the increased cost, the firm will choose to produce more lowcarbon product. On the one hand, it can meet the needs of consumers with low-carbon preference in the market and earn more profits from them. On the other hand, only by producing enough low-carbon products can the firm's total carbon emissions be reduced, so that the actual carbon emissions are lower than the quota allocated by the government. Only in this way can the firm reduce the impact of cap-and-trade policy on the firm and improve the possibility of increasing profit. Moreover, we have previously proved that the demand for low-carbon products under the lowcarbon product strategy is greater than that under the dualproduct strategy. Therefore, the firm will adopt a low-carbon product strategy.

Conversely, if the additional cost for producing lowcarbon products is low, there is less pressure for the firm to recover the cost. So, the firm will produce relatively less lowcarbon products. However, there are still some regular consumers without low-carbon preferences in the market, and the firm can also obtain some profit from them. Thus, in order to better meet the needs of these regular consumers, the firm will choose to produce some ordinary product together with low-carbon product, so that the firm's total profit will be greater than that only producing low-carbon product. Therefore, the firm will adopt a dual-product strategy.

\section{Numerical Example}

This section provides numerical examples to illustrate the above analytical results and gain managerial insights. Due to the difficulty of acquiring accurate data from the firm, we give only some estimated parameters. The parameter values used in this section are as follows: $a=0.6, r=0.4, k=1, e_{0}$ $=0.3, c=0.2$, and $Q=0.8$. 


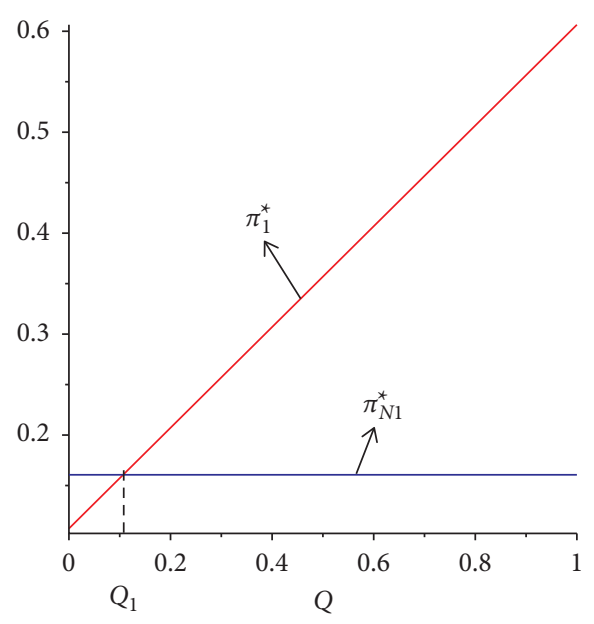

(a)

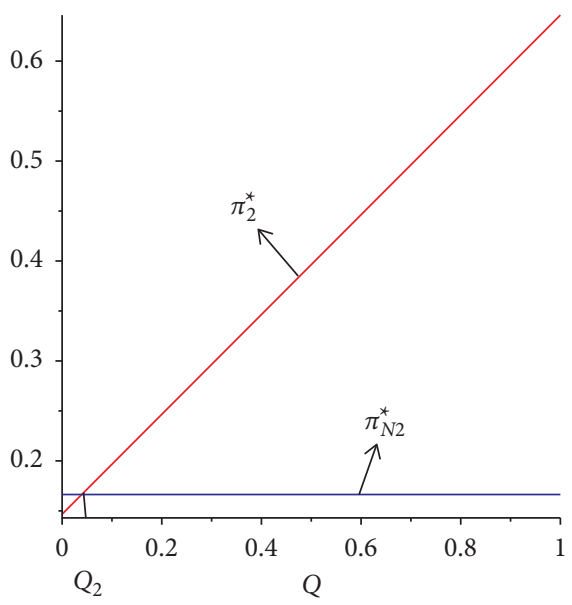

(b)

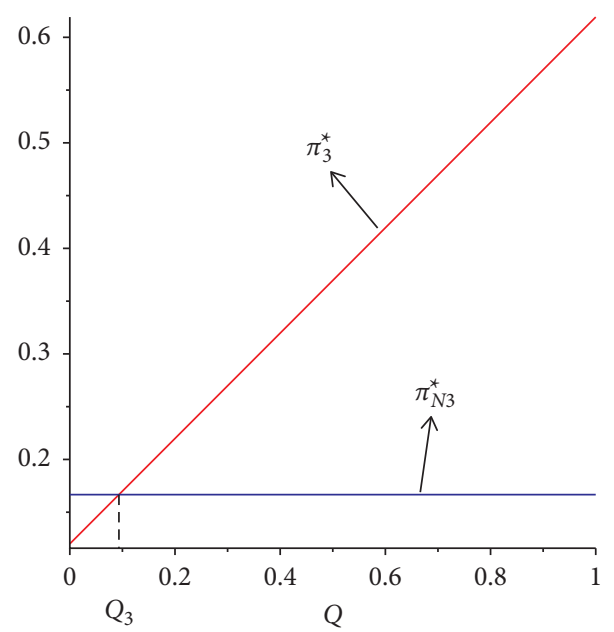

(c)

Figure 3: Comparison of firm profits covered and not covered by the cap-and-trade policy under three product strategies. (a) Ordinary product strategy. (b) Low-carbon product strategy. (c) Dual-product strategy.

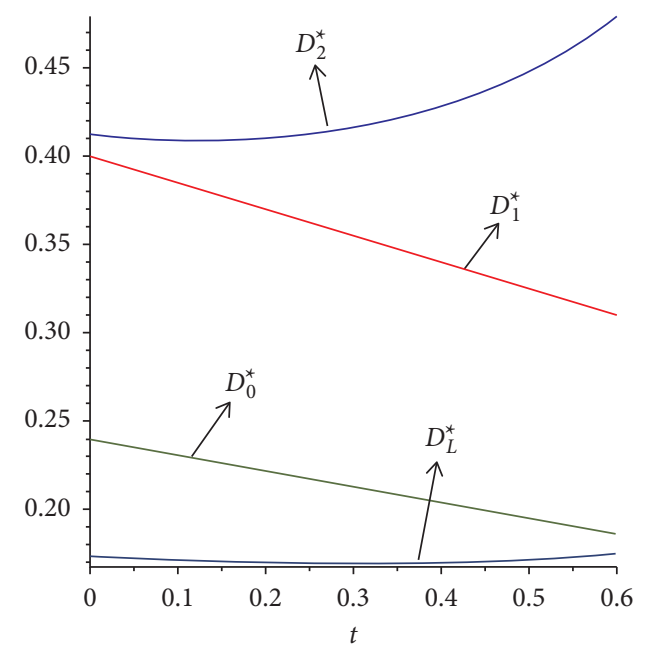

Figure 4: Product demands under three product strategies. 


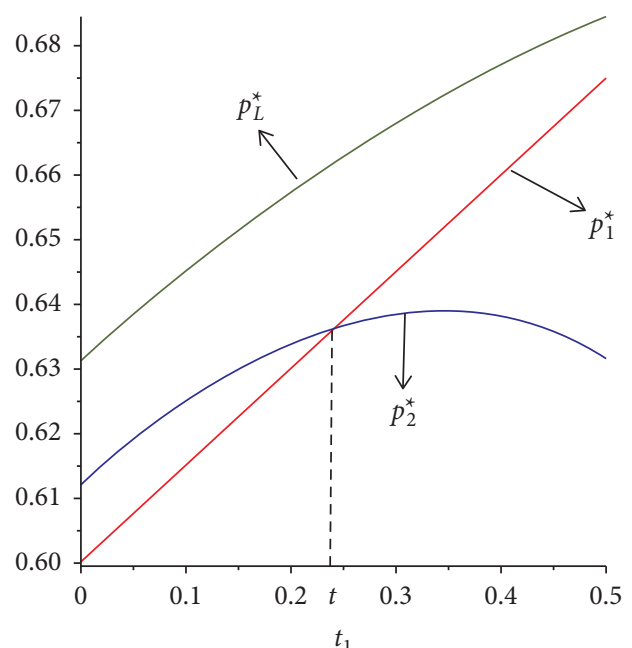

Figure 5: Product prices under three product strategies.

Figure 3 makes a comparative analysis of the firm's profits covered by the cap-and-trade policy and those not covered by this policy and proves that Proposition 3 is consistent with the results. Based on Figure 3, regardless of whether the firm adopts the ordinary product strategy, lowcarbon product strategy, or dual-product strategy, the firm's profits under the influence cap-and-trade policy are different from those not under the influence of this policy. If the firm is under the influence of the cap-and-trade policy, its profits will always rise with the increase in the quota allocated by the government, so it can be seen that the quota has an important impact on the firm's profits. Furthermore, under each product strategy, there is always a threshold $\left(Q_{1}, Q_{2}, Q_{3}\right)$. When the quota allocated by the government exceeds the threshold $\left(Q_{1}, Q_{2}, Q_{3}\right)$, the firm's profits covered by the cap-and-trade policy will be higher than those not covered by this policy; otherwise, they will be lower than those not covered by the cap-and-trade policy.

Figure 4 compares the product demands of each product strategy under the influence of the cap-and-trade policy in a monopoly market. Figure 4 shows that the product demand under the low-carbon product strategy is higher than that under the ordinary product strategy, i.e., $D_{2}>D_{1}$. The demand for ordinary products under the dual-product strategy is lower than that of ordinary products under the ordinary product strategy, i.e., $D_{0}<D_{1}$. The demand for low-carbon products under the dual-product strategy is lower than that under the low-carbon product strategy, i.e., $D_{L}<D_{2}$.

Figure 5 analyzes the product prices under each product strategy. Based on Figure 5, it can be seen that, under the dual-product strategies, the price of the low-carbon product is higher than that of the low-carbon product under the product strategy, i.e., $p_{L}{ }^{*}>p_{2}{ }^{*}$. In addition, there is a threshold $t_{1}=0.24$. When $t>t_{1}=0.24$, the price of the product under the ordinary product strategy is higher than that of the ordinary product under the low-carbon product strategy, i.e., $p_{1}>p_{2}$. When $t<t_{1}=0.24$, the price of the product under the ordinary product strategy is lower than that of the ordinary product under the low-carbon product strategy.

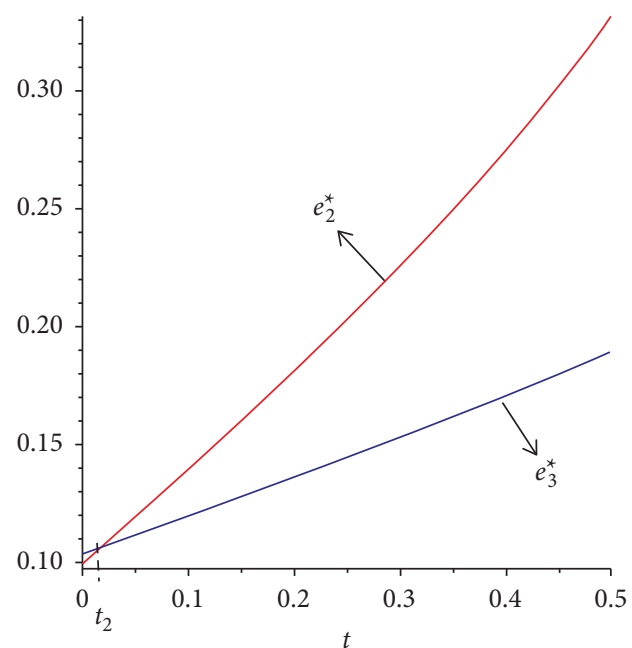

FIgURE 6: Carbon emission reduction level of low-carbon products under the low-carbon product strategy and dual-product strategy.

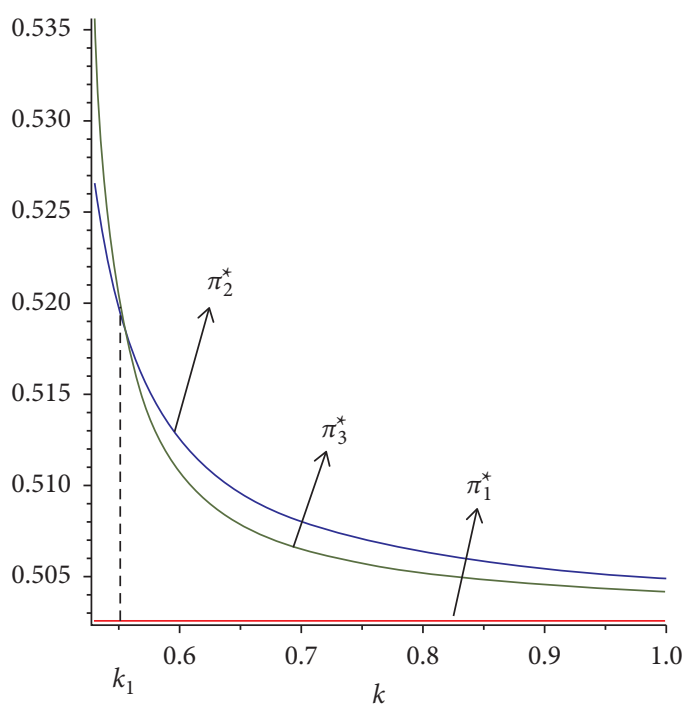

Figure 7: The firm's profits under three product strategies.

Figure 6 analyzes the carbon emission reduction level of the low-carbon product of under the low-carbon product strategy and dual-product strategy in a monopoly market. Figure 6 shows that the values of $e_{2} *$ and $e_{3} *$ both increase with the increase of $t$, which means that the carbon emission reduction level of low-carbon products will continue to increase with the increase of unit carbon price under either low-carbon product strategy or dualproduct strategy. In addition, there is also a threshold $t_{2}=0.02$. When $t>t_{2}=0.02$, the value of $e_{2} *$ is greater than the value of $e_{3} *$, indicating that the carbon emission reduction level of low-carbon products under the lowcarbon product strategy is higher than that under the dual-product strategy. When $t<t_{2}=0.02$, the value of $e_{2} *$ is greater than the value of $e_{3} *$, indicating that the emission reduction level of low-carbon products under the low-carbon product strategy is lower than that under the dual-product strategy. 
Figure 7 analyzes the relationship between the firm's total profits under each product strategy in a monopoly market. Figure 7 shows that the values of $\pi_{2}{ }^{*}$ and $\pi_{3}{ }^{*}$ are always greater than the value of $\pi_{1}{ }^{*}$, indicating that the firm's total profit under the low-carbon product strategy and dual-product strategy is higher than that under the ordinary product strategy. There is also a threshold $k_{1}=0.55$; if $k<k_{1}=0.55$, the value of $\pi_{3}{ }^{*}$ is greater than the value of $\pi_{2}{ }^{*}$, indicating that the firm's profit under the dual-product strategy is higher than that under the low-carbon product strategy; if $k>k_{1}=0.55$, the value of $\pi_{3}{ }^{*}$ is lower than the value of $\pi_{2}{ }^{*}$, indicating that the firm's profit under the dualproduct strategy is lower than that under the low-carbon product strategy. In addition, from Figure 7, we can also see that the profits under the low-carbon product strategy and dual-product strategy decrease with the increase of the additional cost for producing a low-carbon product. However, the profit under the ordinary product strategy is not affected by the cost.

\section{Discussion}

As more and more countries implement policies to motivate firms to take measures to reduce carbon emissions, many firms are faced with the problem of how to change their production strategies according to these policies, which has become a concern of many scholars. At present, many scholars have studied this issue and drawn some conclusions. Du et al. [29] examined three factors that influence firms to adopt low-carbon product strategy under cap-andtrade regulation, which include the additional cost for producing low-carbon products, consumers' preference for low-carbon products, and carbon trading price. They believed that the additional cost is the most important factor that affects firms to produce low-carbon products. They concluded that even if the additional cost involved in producing low-carbon products is high, firms are likely to adopt low-carbon product strategy if consumer preference for low-carbon product is high enough. This is consistent with the conclusion of our research. We also believe that the additional cost is the most important factor preventing firms from adopting a low-carbon product strategy or dualproduct strategy.

However, different from the conclusion of $\mathrm{Du}$ et al. [29], we believe that the firm can gain more profits by adopting low-carbon product strategy as long as certain demand for low-carbon products can be guaranteed. In addition, we provide the thresholds of additional cost that influence the choice between low-carbon product strategy and dualproduct strategy. Du et al. [29] only considers that the firm has two product strategies to choose, while our study considers three product strategies. Du et al. [29] research pointed out that higher carbon trading price can promote the firm to adopt low-carbon product strategy, which we also support. A similar conclusion can also be found in our research. Because a higher carbon trading price can encourage the firm to improve the carbon emission reduction level of product, which can better meet the needs of consumers with low-carbon preference, they can pay a higher premium. The main similarity between our research and $\mathrm{Du}$ et al. [29] research is that we both studied the influence of the additional cost for producing low-carbon products on the choice of low-carbon product strategy under cap-and-trade regulation. The main difference is that we assume that the firm has three product strategies to choose from, whereas $\mathrm{Du}$ et al. [29] only considered two. Meng et al. [30] examined the firm's choice of low-carbon product strategy in competitive markets under the influence of carbon tax policy. The concluded that both the leader and follower in competitive market tend to choose low-carbon product strategy when the carbon tax rate is high, while we study the firm's choice on the low-carbon product strategy in a monopoly market under the influence of cap-and-trade policy. We both believe that government policies will encourage the firms to take measures to reduce carbon emission. The difference is that we studied the effects of cap-and-trade policy, while Meng et al. [30] studied the effects of carbon tax policy. In the research, Meng et al. [30] considered one type of consumers, while we considered two types of consumers.

Our paper's contributions mainly lie in the following three aspects:

Firstly, in this paper, we consider the firm's three product strategies in the presence of cap-and-trade policy, including two single product strategies and a dual-product strategy, and establish the profit optimal model of the three product strategies, while most of the previous literature only considered two single product strategies but did not consider the dual-product strategy. Secondly, our study compares the change of the firm's optimal product strategy before and after the implementation of cap-and-trade policy. However, most of the existing literature only studies the firm's optimal product strategy under government's policy, without studying the change of the firm's optimal product strategy. Thirdly, our study identifies two types of consumers based on their preference for low-carbon product and studies the impact of the proportion of consumers with low-carbon preferences in the market on the firm's decisions, while most of the previous literature on firm's product strategy selection assumed that consumers have the same low-carbon preference.

This article also has certain practical implication. Firstly, our study provides a reference for the firm to choose production strategy in management. Cap-and-trade policy is an important factor in the external environment, the firm cannot escape, but to confront. If properly handled, this policy will not become the firm's burden and may be a way to gain competitive advantage. The policy places a constraint on the firm's carbon emissions but allows the firm to trade the carbon quota, creating both challenges and opportunities. Therefore, understanding the impact of this policy on the firm's decision-making is of positive significance to the management. Secondly, our research can help the policy makers understand the complexity of firms' production strategy selection. Under the influence of cap-and-trade policy, the firm can not only choose two single product strategies, but also adopt an intermediate dual-product strategy. The trade-off on costs and benefits is the decisive factor affecting whether the firm adopts low-carbon 
production strategy. Our research can help the policy makers understand how the carbon quota and the carbon trading price affect the firm's decisions and profit. As can be seen from our research, in addition to consumers' preference for low-carbon products, the proportion of consumers with low-carbon preference in the market also has an important impact on the firm's decision-making and the carbon emission reduction level of the product. Some current literatures show that improving consumers' environmental awareness and preference for low-carbon products can prompt the firm to take measures to reduce carbon emissions, and our study shows that increasing the proportion of consumers with low-carbon preference in the market is also meaningful. Proposition 3 states that when the firm is not covered by cap-and-trade policy, it is optimal to adopt dualproduct strategy. When the firm is covered by this policy, the optimal product strategy can be low-carbon product strategy or dual-product strategies. This can help the policy makers better understand how the firm's change its optimal product strategy. In brief, our research can help policy makers understand the complexity of the firm's decision-making mechanism under the influence of cap-and-trade policy, so as to formulate reasonable and effective policies.

\section{Conclusions}

This paper mainly examines the firm's selection on three product strategies and the product's optimal carbon emission reduction decision in the presence of cap-and-trade policy. These three product strategies include ordinary product strategy, low-carbon product strategy, and dualproduct strategy. In the study, we consider two types of consumers: consumers with preference for low-carbon product and without preference. We first establish an analytical model of consumer utility and firm profits under different product strategies and then solve for the optimal solutions using a game theoretic approach. Finally, we compare and analyze the optimal solutions under each product strategy.

Our analysis revealed the following: before and after the implementation of cap-and-trade policy, the firm's optimal product strategy is different. When the firm is not covered by this policy, the firm's optimal product strategy is dual-product strategy, but when firm is covered by this policy, the firm's optimal product strategy may be dualproduct strategy or low-carbon product strategy; under the influence of cap-and-trade policy, compared with ordinary product strategy, it is beneficial for the firm to adopt low-carbon product strategy or dual-product strategy. Whether to choose low-carbon product strategy or dual-product strategy depends on the additional cost for producing low-carbon product; when the carbon trading price is higher than a threshold, the carbon emission reduction level of the product under the dualproduct strategy is higher than that under low-carbon product strategy, while when the carbon trading price is lower than the threshold, the opposite is true.

We also note a few limitations of our study and provide potential extensions for future research. Firstly, we only examine the firm's decisions in a monopoly market, but in reality, the firm will always face competitors, and its competitors will also affect the decisions on product strategy selection and carbon emission reduction level of product. Therefore, in future research, the situation where two or more firms coexist in the market can be considered. Secondly, we assume that after the firm produces the products, it sells them directly to the consumers. In reality, most firms distribute their products to consumers through retailers, while some firms sell their products through online channel, and even through both online and offline channels. These factors will also affect the firm's decisions, which should be incorporated into the firm's decision-making mechanism. Thirdly, we consider the impact of the firm's decision on its own profit, but not the impact on the overall welfare of the society. In the future study, we can extend the research in this aspect.

\section{Appendix}

\section{A Proofs}

Proof of Lemma 1. We can get that $\partial \pi\left(p_{2}, e_{2}\right) / \partial p_{2}^{2}=-2$, $\partial \pi\left(p_{2}, e_{2}\right) / e p_{2}^{2}=-2$ art $-k$ and $\partial \pi\left(p_{2}, e_{2}\right) / \partial p_{2} \partial e_{2}=a r-k$, let $H$ be a Hessian of $\pi_{2}\left(p_{2}, e_{2}\right)$, noting that $H_{11}<0$ and by the assumption we know that the Hessian is negative definite. Hence, $\pi_{2}\left(p_{2}, e_{2}\right)$ is jointly concave in $p_{2}$ and $e_{2}$, and sets $\partial \pi\left(p_{2}, e_{2}\right) / \partial p_{2}=0$ and $\partial \pi\left(p_{2}, e_{2}\right) / \partial e_{2}=0$, then we can solve them to obtain $p_{2}{ }^{*}$ and $e_{2}{ }^{*}$. By substituting them into $\pi_{2}\left(p_{2}, e_{2}\right)$, we can obtain $D_{2}{ }^{*}$ and $\pi_{2}{ }^{*}$.

Proof of Lemma 2. The process of obtaining the optimal solutions is similar to that in Lemma 1; thus, we omit it.

Proof of Proposition 1

(i) Calculate $\partial D_{2}{ }^{*} / \partial r$, which equals $k\left(e_{0} t+c-1\right) /$ $a^{2} r^{2}+2 a r t+t^{2}-2 k$. From Assumption 3, we obtain $e_{0} t+c-1<0$ and $a^{2} r^{2}+2 \operatorname{art}+t^{2}-2 k<0$; therefore, we have $\partial D_{2}{ }^{*} / \partial r>0$.

(ii) Similarly, the authors have $D_{L}{ }^{*} / \partial r>0$ and $\partial D_{L}{ }^{*} /$ $\partial r<0$.

Proof of Proposition 2

(i) Calculate $\partial e_{2}{ }^{*} / \partial r$, which equals $a\left(a^{2} r^{2}+2\right.$ art $+t^{2}+$ $2 k)\left(e_{0} t+c-1\right) /\left(a^{2} r^{2}+2 \operatorname{art}+t^{2}-2 k\right)$. Since we have $\left(a^{2} r^{2}+2 a r t+t^{2}-2 k\right)^{2}>0, \quad a\left(a^{2} r^{2}+2\right.$ art + $\left.t^{2}+2 k\right)^{2}>0$, and $e_{0} t+c-1<0$. Therefore, we have $\partial e_{2}{ }^{*} / \partial r>0$.

(ii) Similarly, the authors have $\partial e_{3}{ }^{*} / \partial r=-2\left(e_{0} t+c-\right.$ 1) $(a+t) k /\left(a^{2} r+2 a r t+r t^{2}-2 k\right)^{2}>0$.

When the firm is not covered by the cap-and-trade policy, the profit functions under the ordinary product strategy, low-carbon product strategy and dual-product strategy are $\pi_{N 1}=\left(p_{N 1}-c\right) D_{N 1}, \pi_{N 2}=\left(p_{N 2}-c\right) D_{N 2}-$ $1 / 2 k e_{N 2}^{2}$ and $\pi_{N 3}=\left(p_{N 0}-c\right) D_{N 0}+\left(p_{N L}-c\right) D_{N L}-1 / 2 e_{N 3}^{3}$. 
By calculating the optimal solutions of profit functions, the authors obtain the firm's profits under each product strategy.

\section{Proof of Proposition 3}

(i) Calculate $\pi_{1}{ }^{*}-\pi_{N 1}{ }^{*}$, which equals $1 / 4 t\left(e_{0} 2 t+2 c e_{0}\right.$ $\left.+4 Q-2 e_{0}\right)$.

Since $e_{0} 2 t+2 c e_{0}+4 \mathrm{Q}-2 e_{0}$ is a linear increasing function in $Q$ and the coefficient is positive.

Solve $e_{0} 2 t+2 c e_{0}+4 Q-2 e_{0}=0$ and obtain $Q_{1}=1 /$ $2\left(e_{0}-e_{0} t-c e_{0}\right)$. Therefore, the authors have $\pi_{1}{ }^{*}>\pi_{N 1}{ }^{*}$ for $Q>Q_{1}$ and $\pi_{1}{ }^{*}<\pi_{N 1}{ }^{*}$, otherwise.

(ii) Similarly, we have $\pi_{2}{ }^{*}>\pi_{\mathrm{N} 2}{ }^{*}$ for $Q>Q_{2}$ and $\pi_{2}{ }^{*}<\pi_{N 2}{ }^{*}$, otherwise.

(iii) Similarly, we have $\pi_{3}{ }^{*}>\pi_{N 3}{ }^{*}$ for $Q>Q_{3}$ and $\pi_{3}{ }^{*}<\pi_{N 3}{ }^{*}$, otherwise.

Proof of Proposition 4. Calculate $\pi_{N 2}{ }^{*}-\pi_{N 1}{ }^{*}$, which equals $-1 / 4(c-1)^{2} a^{2} r^{2} / a^{2} r^{2}-2 k$. From Assumption 3, we obtain $c-1<0$ and $a^{2} r^{2}-2 k<0$. Therefore, we have $\pi_{N 2}{ }^{*}>\pi_{N 1}{ }^{*}$.

Calculate $\pi_{N 3}{ }^{*}-\pi_{N 2}{ }^{*}$, which equals $-1 / 4(c-1)^{2} a^{2} r^{2}$ / $\left(a^{2} r-2 k\right)-\left(a^{2} r^{2}-2 k\right)$. From assumption, we obtain $c-1<0, a^{2} r^{2}-2 k<0$ and $a^{2} r-2 k<0$. Therefore, we have $\pi_{N 3}{ }^{*}>\pi_{N 2}{ }^{*}$.

\section{Proof of Proposition 5}

(i) Calculate $D_{2}{ }^{*}-D_{1}{ }^{*}$, which equals $1 / 2(a+t)^{2}$ $\left(e_{0} t+c-1\right) /(a r+t)^{2}-2 k$. From Assumption 3, we obtain $e_{0} t+c-1<0$ and $(a r+t)^{2}-2 k<0$. Therefore, we have $D_{2}{ }^{*}>D_{1}{ }^{*}$.

(ii) Calculate $p_{2}{ }^{*}-p_{1}{ }^{*}$, which equals $1 / 2(a r-t)$ $(a r-t)\left(e_{0} t+c-1\right) /(a r-t)^{2}-2 k$. Since The authors have $e_{0} t+c-1<0, \quad(a r+t)^{2}-2 k<0$, and $a r+t>0$, then $a r-t$ is a linear increasing function in $t$. Solve $a r-t=0$ and obtain $t_{1}=a r$; therefore, the authors have $p_{2}{ }^{*}>p_{1}{ }^{*}$ for $t<t_{1}$ and $p_{2}{ }^{*}<p_{1}{ }^{*}$, otherwise.

\section{Proof of Proposition 6}

(i) We have $p_{0}{ }^{*}=1 / 2\left(e_{0} t+c+1\right)$ and $p_{1}{ }^{*}=1 / 2\left(e_{0} t+\right.$ $c+1)$. Therefore, we have $p_{0}{ }^{*}=p_{1}{ }^{*}$.

(ii) Calculate $D_{0}{ }^{*}-D_{1}{ }^{*}$, which equals $1 / 2 r\left(e_{0} t+c-1\right)$. By assumption, the authors obtain $e_{0} t+c-1<0$. Therefore, the authors have $D_{0}{ }^{*}<D_{1}{ }^{*}$.

Proof of Proposition 7. Calculate $p_{L}{ }^{*}-p_{2}{ }^{*}$, which equals $-(r-1)\left(a^{3} r^{2}+a^{2} r^{2} t^{2}+a^{2} r t^{2}+a r t^{3}-a^{2} k r-k t^{2}\right)\left(e_{0} t+\right.$ $c-1) /\left(a^{2} r+2 a r t+r t^{2}-2 k\right)\left(a^{2} r^{2}+2 a r t+t^{2}-2 k\right)$. From assumption, we obtain $e_{0} t+c-1<0, a^{2} r^{2}+2 a r t+t^{2}-$ $2 k<0, a^{2} r+2 a r t+r t^{2}-2 k<0$, and $a^{3} r^{2}+a^{2} r^{2} t^{2}+a^{2} r t^{2}$ $+a r t^{3}-a 2 k r-k t^{2}<0$; therefore, we have $p_{L}{ }^{*}>p_{2}{ }^{*}$.
Calculate $D_{L}{ }^{*}-D_{2}{ }^{*}$, which equals $k\left(e_{0} t+c-1\right)(r-$ 1) $\left(a^{2} r^{2}+a^{2} r+2 a r t-2 k\right) /\left(a^{2} r+2 a r t+r t^{2}-2 k\right) \quad\left(a^{2} r^{2}+\right.$ $\left.2 a r t+t^{2}-2 k\right)$. Since we have $e_{0} t+c-1<0, a^{2} r^{2}+$ $2 a r t+t^{2}-2 k<0, a^{2} r+2 a r t+r t^{2}-2 k<0$ and $a^{2} r^{2}+a^{2} r$ +2 art $-2 k<0$; therefore, we have $D_{L}{ }^{*}<D_{2}{ }^{*}$.

Proof of Proposition 8. Calculate $e_{3}{ }^{*}-e_{2}{ }^{*}$, which equals $(r-1)\left(a^{3} r^{2}+a^{2} r^{2}+a^{2} r t+a r t^{2}-2 k t\right)\left(e_{0} t+c-1\right) /\left(a^{2} r+\right.$ $\left.2 a r t+r t^{2}-2 k\right)\left(a^{2} r^{2}+2 a r t+t^{2}-2 k\right)$. By assumption, we have $a^{2} r+2 a r t+r t^{2}-2 k<0$ and $a^{2} r^{2}+2 a r t+t^{2}-2 k<0$; then, we find that the denominator is positive. For the nominator, we obtain $e_{0} t+c-1>0$ and $r-1<0$. Let $N=a^{3} r^{2}+a^{2} r^{2}+a^{2} r t+a r t^{2}-2 k t$, which is quadratic function in $t$, and the coefficient of $a r$ is positive. Let $N=0$ and solve for $t$ to obtain one real solution $t_{2}$. Therefore, we have $e_{3}{ }^{*}>e_{2}{ }^{*}$ for $t>t_{2}$ and $e_{3}{ }^{*}<e_{2}{ }^{*}$, otherwise.

Proof of Proposition 9. Calculate $\pi_{2}{ }^{*}-\pi_{1}{ }^{*}$, which equals $-1 / 4\left(e_{0} t+c-1\right)^{2}(a+t)^{2} /(a r+t)^{2}-2 k$. By assumption, we obtain $(a r+t)^{2}-2 k<0$. Then, we can conclude $\pi_{2}{ }^{*}>\pi_{1}{ }^{*}$.

Proof of Proposition 10. We can calculate $\pi_{3}{ }^{*}-\pi_{1}{ }^{*}$, which equals $-1 / 4 r^{2}\left(e_{0} t+c-1\right)^{2}(a+t)^{2} /(a+t)^{2}-2 k$. By assumption, we obtain $r(a+t)^{2}-2 k<0$. Then, we can conclude $\pi_{3}{ }^{*}>\pi_{1}{ }^{*}$.

Proof of Proposition 11. We can calculate $\pi_{3}{ }^{*}-\pi_{2}{ }^{*}$, which equals $1 / 4\left(e_{0} t+c-1\right)^{2}(1-r)\left[(a+t)^{2}(a r+t)^{2} r-2 k t(2 a r\right.$ $+r t+t)] /\left(a^{2} r+2 a r t+r t^{2}-2 k\right)\left(a^{2} r^{2}+2 a r t+t^{2}-2 k\right)$. By assumption, we have $a^{2} r+2$ art $+r t^{2}-2 k<0$ and $a^{2} r^{2}+$ 2 art $+t^{2}-2 k<0$, then we find that the denominator is positive. For the nominator, we obtain $\left(e_{0} t+c-1\right)^{2}>0$ and $1-r>0$. Let $M=(a+t)^{2}(a r+t)^{2} \quad r-2 k t(2 a r+r t+t)$, which is a decreasing function in $k$, and the coefficient is negative. Let $M=0$ and solve for $k$ to obtain one real solution $k_{1}=(a+t)^{2}(a r+t)^{2} / 2 t(2 \operatorname{art}+r t+t)$. Therefore, we have $\pi_{3}{ }^{*}>\pi_{2}{ }^{*}$ for $k>k_{1}$ and $\pi_{3}{ }^{*}<\pi_{2}{ }^{*}$ otherwise.

\section{B. Proof of Satisfied Condition in Lemma 2}

From Lemma 2, the authors know $p_{L}{ }^{*}=r(a+t)\left(a e_{0} t+\right.$ $a c+t)-k\left(e_{0} t+c+1\right) / r(a+t)^{2}-2 k p_{0}{ }^{*}=1 / 2\left(e_{0} t+c+1\right)$, $e_{3}{ }^{*}=r(a+t)\left(e_{0} t+c-1\right) / r(a+t)^{2}-2 k$. First, the authors compare the value of $p_{L}{ }^{*}$ with the value of $p_{0}{ }^{*}+a e$. By calculating, the authors get $p_{0}+a e_{3}-p_{L}=1 / 2 r(a+t)^{2}$ $\left(e_{0} t+c-1\right) / r(a+t)^{2}-2 k$. From Assumption 3, the authors can obtain $e_{0} t+c-1<0$ and $r(a+t)^{2}-2 k<0$ (see the details in Appendix A). Then, the authors can prove $p_{0}+$ $a e_{3}>p_{L}$. Similarly, the authors can prove $p_{L}-p_{0}=$ $1 / 2 r(a+t)^{2}(a+t)\left(e_{0} t+c-1\right) / r(a+t)^{2}-2 k>0$. Therefore, the values of $p_{0}{ }^{*}$ and $p_{L}{ }^{*}$ in Lemma 2 satisfy the relation $p_{0} \leq p_{L} \leq p_{0}+a e_{3}$.

\section{Data Availability}

No data were used to support this study. 


\section{Conflicts of Interest}

The authors declare that there are no conflicts of interest regarding the publication of this article.

\section{Acknowledgments}

This work was supported by the National Natural Science Foundation of China (Grant/Award nos. 72071047 and 71572034).

\section{References}

[1] Z. Wang and C. Wang, "How carbon offsetting scheme impacts the duopoly output in production and abatement: analysis in the context of carbon cap-and-trade," Journal of Cleaner Production, vol. 103, pp. 715-723, 2015.

[2] $\mathrm{X} . \mathrm{Xu}, \mathrm{X} . \mathrm{Xu}$, and $\mathrm{P} . \mathrm{He}$, "Joint production and pricing decisions for multiple products with cap-and-trade and carbon tax regulations," Journal of Cleaner Production, vol. 112, no. 20, pp. 4093-4106, 2016.

[3] H. S. Chan, S. Li, and F. Zhang, "Firm competitiveness and the European Union emissions trading scheme," Energy Policy, vol. 63, pp. 1056-1064, 2013.

[4] F. Adaman, N. Karalı, G. Kumbaroğlu, İ. Or, B. Özkaynak, and Ü. Zenginobuz, "What determines urban households' willingness to pay for $\mathrm{CO} 2$ emission reductions in Turkey: a contingent valuation survey," Energy Policy, vol. 39, no. 2, pp. 689-698, 2011.

[5] Z. Liu, T. D. Anderson, and J. M. Cruz, "Consumer environmental awareness and competition in two-stage supply chains," European Journal of Operational Research, vol. 218, no. 3, pp. 602-613, 2012.

[6] V. O'Connell, Green Goods, Red Flag, Wall Street Journal, New York, NY, USA, 2010.

[7] European Commission, "Attitudes of European citizens towards the environment," Special Eurobarometer, Brussels, Belgium, vol. 68, no. 2, pp. 1-94, 2008.

[8] F. X. Aguilar and R. P. Vlosky, "Consumer willingness to pay price premiums for environmentally certified wood products in the U.S," Forest Policy and Economics, vol. 9, no. 8, pp. 1100-1112, 2007.

[9] C. A. Roheim, F. Asche, and J. I. Santos, "The elusive price premium for ecolabelled products: evidence from seafood in the UK market," Journal of Agricultural Economics, vol. 62, no. 3, pp. 655-668, 2011.

[10] K. H. Kang, L. Stein, C. Y. Heo, and S. Lee, "Consumers' willingness to pay for green initiatives of the hotel industry," International Journal of Hospitality Management, vol. 31, no. 2, pp. 564-572, 2012.

[11] G. Akehurst, C. Afonso, and H. Martins Gonçalves, "Reexamining green purchase behaviour and the green consumer profile: new evidences," Management Decision, vol. 50, no. 5, pp. 972-988, 2012.

[12] Y. Zhang, C. Xiao, and G. Zhou, "Willingness to pay a price premium for energy-saving appliances: role of perceived value and energy efficiency labeling," Journal of Cleaner Production, vol. 242, Article ID 118555, 2020.

[13] Q. Tan, K. Imamura, K. Nagasaka, and M. Inoue, "consumer price premiums for FSCLabeled wood flooring: a comparison of five Chinese cities," BioProducts Business, vol. 5, no. 2, pp. 13-24, 2020.

[14] K. Higgins, W. G. Hutchinson, and A. Longo, "Willingnessto-pay for eco-labelled forest products in northern Iireland: an experimental auction approach," Journal of Behavioral and Experimental Economics, vol. 87, Article ID 101572, 2020.

[15] S. Benjaafar, Y. Li, and M. Daskin, "Carbon footprint and the management of supply chains: insights from simple models," IEEE Transactions on Automation Science and Engineering, vol. 10, no. 1, pp. 99-116, 2013.

[16] K. Cao, X. Xu, Q. Wu, and Q. Zhang, "Optimal production and carbon emission reduction level under cap-and-trade and low carbon subsidy policies," Journal of Cleaner Production, vol. 167, pp. 505-513, 2017.

[17] X. Xu, W. Zhang, P. He, and X. Xu, "Production and pricing problems in make-to-order supply chain with cap-and-trade regulation," Omega, vol. 66, pp. 248-257, 2017.

[18] T. Zhang, "Which policy is more effective, carbon reduction in all industries or in high energy-consuming Industries?-From dual perspectives of welfare effects and economic effects," Journal of Cleaner Production, vol. 216, pp. 184-196, 2019.

[19] D. Zhou, Y. An, D. Zha, F. Wu, and Q. Wang, "Would an increasing block carbon tax be better? A comparative study within the Stackelberg Game framework," Journal of Environmental Management, vol. 235, pp. 328-341, 2019.

[20] J. Hussain, Y. Pan, G. Ali, and Y. Xiaofang, "Pricing behavior of monopoly market with the implementation of green technology decision under emission reduction subsidy policy," The Science of the Total Environment, vol. 709, Article ID 136110, 2020.

[21] W. Zhang, X. Zhang, F. Liu, Y. Huang, and Y. Xie, "Evaluation of the urban low-carbon sustainable development capability based on the TOPSIS-BP neural network and grey relational analysis," Complexity, vol. 2020, Article ID 6616988, 16 pages, 2020.

[22] R. Yang, W. Tang, and J. Zhang, "Technology improvement strategy for green products under competition: the role of government subsidy," European Journal of Operational Research, vol. 289, no. 2, pp. 553-568, 2021.

[23] J. Lu and X. C. Sun, "Carbon regulations, production capacity, and low-carbon technology level for new products with incomplete demand information," Journal of Cleaner Production, vol. 282, Article ID 124551, 2021.

[24] W. Zhang, M. Zhang, S. Wu, and F. Liu, "A complex path model for low-carbon sustainable development of enterprise based on system dynamics," Journal of Cleaner Production, vol. 321, Article ID 128934, 2021.

[25] X. Gong and S. X. Zhou, "Optimal production planning with emissions trading," Operations Research, vol. 61, no. 4, pp. 908-924, 2013

[26] T. Shu, Q. Wu, S. Chen, S. Wang, K. K. Lai, and H. Yang, "Manufacturers'/remanufacturers' inventory control strategies with cap-and-trade regulation," Journal of Cleaner Production, vol. 159, no. 15, pp. 11-25, 2017.

[27] S. Wang, L. Wan, T. Li, B. Luo, and C. Wang, "Exploring the effect of cap-and-trade mechanism on firm's production planning and emission reduction strategy," Journal of Cleaner Production, vol. 172, pp. 591-601, 2018.

[28] Z. Wang, A. E. I. Brownlee, and Q. Wu, "Production and joint emission reduction decisions based on two-way cost-sharing contract under cap-and-trade regulation," Computers \& Industrial Engineering, vol. 146, Article ID 106549, 2020.

[29] S. F. Du, W. Z. Tang, and M. L. Song, "Low-carbon production with low-carbon premium in cap-and-trade regulation," Journal of Cleaner Production, vol. 2, pp. 1-11, 2016.

[30] X. Meng, Z. Yao, J. Nie, Y. Zhao, and Z. Li, "Low-carbon product selection with carbon tax and competition: effects of 
the power structure," International Journal of Production Economics, vol. 200, pp. 224-230, 2018.

[31] S. Zhang, C. Wang, C. Yu, and Y. Ren, "Governmental cap regulation and manufacturer's low carbon strategy in a supply chain with different power structures," Computers \& Industrial Engineering, vol. 134, pp. 27-36, 2019.

[32] X. Zhang, Y. Jin, and C. Shen, "Manufacturers' green investment in a competitive market with a common retailer," Journal of Cleaner Production, vol. 276, pp. 123-164, 2020.

[33] L. Yang, Q. Zhang, and J. Ji, "Pricing and carbon emission reduction decisions in supply chains with vertical and horizontal cooperation," International Journal of Production Economics, vol. 191, pp. 286-297, 2017.

[34] J. Ji, Z. Zhang, and L. Yang, "Carbon emission reduction decisions in the retail-/dual-channel supply chain with consumers' preference," Journal of Cleaner Production, vol. 141, pp. 852-867, 2017. 